Check for updates

Cite this: RSC Adv., 2017, 7, 25566

Received 17th March 2017

Accepted 4th May 2017

DOI: $10.1039 / c 7 r a 03190 d$

rsc.li/rsc-advances

\section{Phosphorescent platinum(II) complexes bearing
pentafluorosulfanyl substituted cyclometalating \\ Phosphorescent platinum(II) complexes bearing
pentafluorosulfanyl substituted cyclometalating ligands $\uparrow+$}

\author{
Adam F. Henwood, ${ }^{a}$ James Webster, ${ }^{a}$ David Cordes, (D) ${ }^{\text {b }}$ Alexandra M. Z. Slawin, ${ }^{b}$ \\ Denis Jacquemin (D) *cd and Eli Zysman-Colman (D) *a
}

\begin{abstract}
The first examples of phosphorescent platinum(II) complexes bearing pentafluorosulfanyl (-SF $)_{5}$ substituted cyclometalating ligands $\left(C^{\wedge} N\right)$ are reported. These complexes are of the form $\left[\operatorname{Pt}^{\prime}\left(C^{\wedge} N\right)(\right.$ pivacac)], where pivacac is $2,2^{\prime}, 6,6^{\prime}$-tetramethylheptane-3,5-dionate. Modifying the phenyl ring of the $\mathrm{C}^{\wedge} \mathrm{N}$ ligand to incorporate one strongly electron-withdrawing $-\mathrm{SF}_{5}$ group has important effects on the photophysical and electrochemical properties of the complex that are dependent on the regiochemistry of the substituent. In a meta position with respect to the $\mathrm{Pt}-\mathrm{C}_{\mathrm{C}_{\wedge N} \mathrm{~N}}$ bond, the substituent exerts a predominantly stabilising effect on the lowest triplet excited state that red-shifts the emission of the complex compared to the reference [Pt(ppy)(pivacac)], 1, where ppy is 2-phenylpyridinato. When the $-\mathrm{SF}_{5}$ group is located para to the $\mathrm{Pt}-\mathrm{C}_{\mathrm{C}^{\wedge} \mathrm{N}}$ bond, it does not affect the triplet state directly, and the electron-withdrawing group stabilises the metalbased orbitals, resulting in a blue-shift of the emission. In the solid-state all three complexes are mechanochromic, and can display excimeric emission originating from intermolecular $\pi-\pi *$ interactions, but the relative emission intensities of the monomeric and dimeric excited states correlate with the steric congestion of the metal centre, and in particular the regiochemistry of the $-\mathrm{SF}_{5}$ group. We relate these findings with observations in the crystal structures.
\end{abstract}

\section{Introduction}

Phosphorescent transition metal complexes have for many years served as materials in a wide variety of applications including but not limited to photoredox catalysis, ${ }^{1}$ solar fuels, ${ }^{2}$ biological imaging ${ }^{3}$ and electroluminescent devices. ${ }^{4}$ Typically these complexes are comprised of metal ions such as $\operatorname{Ir}(\mathrm{III})$, $\mathrm{Ru}(\mathrm{II})$, and $\mathrm{Re}(\mathrm{I})$, all of which possess an octahedral coordination geometry. However, metal complexes displaying alternative geometries ${ }^{5}$ such as trigonal planar $\left[\mathrm{Cu}(\mathrm{I})^{6}\right]$, linear $\left[\mathrm{Pd}(0) ;^{7} \mathrm{Au}(\mathrm{I})^{8}\right]$

${ }^{a}$ Organic Semiconductor Centre, EaStCHEM School of Chemistry, University of St Andrews, St Andrews, Fife, KY16 9ST, UK. E-mail: eli.zysman-colman@st-andrews. ac.uk; Web: http://www.zysman-colman.com; Fax: +44-1334-463808; Tel: +44-1334463826

${ }^{b}$ EaStCHEM School of Chemistry, University of St. Andrews, St. Andrews, KY16 9ST, Fife, UK

'Laboratoire CEISAM, UMR CNRS-6230, Université de Nantes, 2 Rue de la Houssinière, BP 92208, 44322 Nantes Cedex 3, France. E-mail: Denis.Jacquemin@univ-nantes.fr ${ }^{d}$ Institut Universitaire de France, 1 rue Descartes, F-75231 Paris Cedex 05, France

$\dagger$ Electronic supplementary information (ESI) available: Synthesis, characterization, details of photophysical measurements and supplementary theoretical data can be found in the extra supporting information (ESI) document. CCDC 1532909 and 1532910 contain the supplementary crystallographic data for this paper. For ESI and crystallographic data in CIF or other electronic format see DOI: $10.1039 / \mathrm{c} 7 \mathrm{ra} 03190 \mathrm{~d}$

‡ Data supporting this study are available at http://dx.doi.org/10.17630/4b7e9abe-51b4-4189-8db2-ec365cb9839d. and in particular square planar complexes such as those based on $\mathrm{Pt}(\mathrm{II}),{ }^{9} \mathrm{Pd}(\mathrm{II})^{10}$ and $\mathrm{Au}(\mathrm{III})^{11}$ can also display an attractive and useful range of photophysical properties. Among these, $\mathrm{Pt}$ (II) complexes are the most widely explored due to the wide colour tunability and high photoluminescence quantum yields associated with these complexes.

One of the archetypal phosphorescent Pt(II) complex families is of the form $\left[\mathrm{Pt}\left(\mathrm{C}^{\wedge} \mathrm{N}\right)\left(\mathrm{O}^{\wedge} \mathrm{O}\right)\right]$, containing two bidentate chelates, where $\mathrm{C}^{\wedge} \mathrm{N}$ denotes a cyclometalating ligand such as 2-phenylpyridinato (ppy) and $\mathrm{O}^{\wedge} \mathrm{O}$ is a $\beta$-diketonate ligand, such as 2,2',6,6'-tetramethylheptane-3,5-dionate (pivacac). ${ }^{12}$ Depending on the nature of the $\mathrm{C}^{\wedge} \mathrm{N}$ ligand, $\left[\mathrm{Pt}\left(\mathrm{C}^{\wedge} \mathrm{N}\right)\left(\mathrm{O}^{\wedge} \mathrm{O}\right)\right]$ complexes phosphoresce from a metal-to-ligand charge transfer $\left({ }^{3} \mathrm{MLCT}\right)$ and/or a ligand centred $\left({ }^{3} \mathrm{LC}\right)$ state. ${ }^{12 a, 13}$ However, the square planar geometry of $\mathrm{Pt}(\mathrm{II})$ complexes permits a secondary interaction facilitated by mixing filled $5 \mathrm{~d}_{z^{2}}$ and empty $6 \mathrm{p}_{z}$ orbitals localized on the metals of closely spaced complexes. ${ }^{14}$ Formation of these dimers results in greatly red-shifted excimer emission from a distinct metal-metal-to-ligand charge transfer $\left({ }^{3} \mathrm{MMLCT}\right)$ state $^{15}$ or from interligand $\pi-\pi^{*}$ interactions, as also reported in purely organic systems. ${ }^{16}$ Generally, excimer emission can only be observed in concentrated media such as neat films, although certain dinuclear $\mathrm{Pt}(\mathrm{II})$ complexes, which are predisposed to form tight Pt $\cdots \mathrm{Pt}$ interactions, can emit exclusively from ${ }^{3} \mathrm{MMLCT}$ states even in dilute solution or doped films. ${ }^{17}$ 
Careful control over the relative contributions of the individual higher energy monomeric and lower energy excimeric states has led to many reports of $\mathrm{Pt}$ (II) complexes emitting white light. This feature has been exploited for the design of singlemolecule white OLEDs (WOLEDs), ${ }^{18}$ as well as more recently for sensing applications. ${ }^{17}$

In the solid-state, it is common for these complexes to selfassemble in linear-chains to maximise bonding interactions between the complexes. ${ }^{14}$ Given the weak nature of the Pt-Pt bonding interaction, it is unsurprising that even minor structural variations in the ligand scaffold can influence the stacking arrangement. For example, $\mathrm{Pt}\left(\mathrm{N}^{\wedge} \mathrm{N}\right)(\mathrm{X})_{2}$ (where $\mathrm{N}^{\wedge} \mathrm{N}$ is a bidentate diimine ligand such as $2,2^{\prime}$-bipyridine and $\mathrm{X}$ is a monodentate anionic ligand such as chloride) complexes form columnar assemblies in the solid-state with the ligands arranged in an anti-parallel fashion to maximise weak intermolecular bonding effects between the occupied orbitals of the anionic ligands and the vacant $\pi^{*}$ orbitals situated on the diimine ligands. ${ }^{14}$ Stronger effects, such as the electrostatics in the famous example of Magnus' salt $\left[\mathrm{Pt}\left(\mathrm{NH}_{3}\right)_{4}\right]\left[\mathrm{PtCl}_{4}\right],{ }^{5,19}$ can further facilitate the Pt $\cdots$ Pt bonding phenomena, while sterically encumbering ligand substitutions can, on the other hand, disrupt these Pt $\cdots$ Pt interactions. ${ }^{20}$

Regiochemistry is a particularly important consideration, since there are numerous possible orientations these assemblies might adopt, with respect to both the metal centres (eclipsed and staggered) and the ligands (for example: syn, where both $\mathrm{C}^{\wedge} \mathrm{N}$ and $\mathrm{O}^{\wedge} \mathrm{O}$ ligands are arranged in an overlapping fashion, or anti where the ancillary ligands are directed away from each other to maximise $\mathrm{C}^{\wedge} \mathrm{N}^{\cdots} \mathrm{C}^{\wedge} \mathrm{N} \pi-\pi$ interactions - see Fig. 1). As such, the predisposition to adopt a particular orientation is influenced by small changes in the ligand scaffolds. Furthermore, it is not uncommon for more than one packing arrangement to be possible for a particular complex, giving rise to phenomena such as polymorphism ${ }^{21}$ and mechanochromism. ${ }^{22}$

In our group, we recently reported on the photophysical properties of a series of cationic iridium complexes containing $\mathrm{C}^{\wedge} \mathrm{N}$ ligands bearing pentafluorosulfanyl $\left(-\mathrm{SF}_{5}\right)$ substituents. ${ }^{23}$ The electron-withdrawing $-\mathrm{SF}_{5}$ group was chosen as an alternative substituent for blue-shifting the emission of these complexes to the commonly used 2-(4,6-difluorophenyl)pyridinato, dFppy, ligand due to the interest in designing emitters that do not possess $\mathrm{C}_{\text {Aryl }}-\mathrm{F}$ bonds as these have been shown to be unstable in

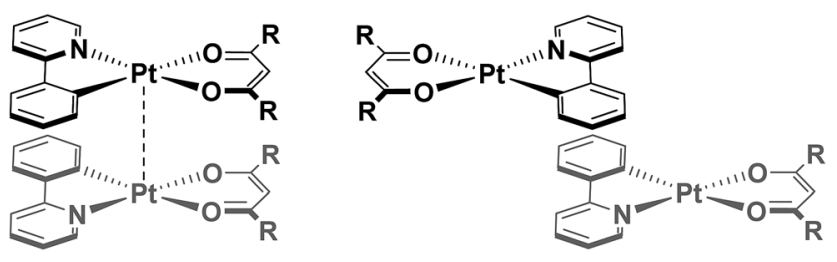

Fig. $1 \mathrm{Pt}(॥)$ complexes arranged in a syn-orientation (left) of the ligands showing both $\pi-\pi$ interactions and metal-metal interactions and in an anti-orientation (right) of the ligands with $C^{\wedge} N \cdots C^{\wedge} N \pi-\pi$ interactions but without further interactions owing to large Pt...Pt and

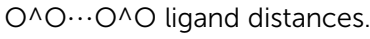

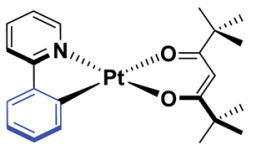

1

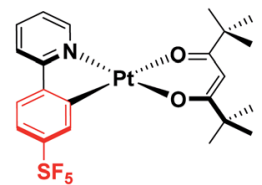

2

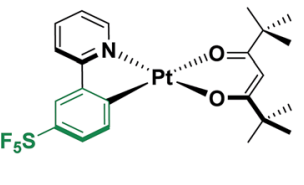

3
Chart 1 Complexes synthesised and characterised in this study.

electroluminescent devices. ${ }^{24}$ The $-\mathrm{SF}_{5}$ group is both chemically stable and sterically bulky, which makes it an attractive alternative functional group to fluorinated phenyl rings. However, for Ir(III) complexes, which adopt pseudo-spherical geometries, steric bulk does not significantly influence the optoelectronics of the complexes, although it can be important in influencing the photoluminescence quantum yield $\left(\Phi_{\mathrm{PL}}\right)$ by suppressing nonradiative decay pathways. ${ }^{25}$ Thus in this study we explore the effect of the addition of the $-\mathrm{SF}_{5}$ substituent on the $\mathrm{C}^{\wedge} \mathrm{N}$ ligand of heteroleptic square planar $\mathrm{Pt}(\mathrm{II})$ complexes of the form $\left[\mathrm{Pt}\left(\mathrm{C}^{\wedge} \mathrm{N}\right)\left(\mathrm{O}^{\wedge} \mathrm{O}\right)\right]$, with the goal of not only documenting the magnitude of the blue-shifting power of this moiety, but also to understand how its steric bulk, and the regiochemistry of this steric bulk, influence the assembly of dimeric species in the solid state and the subsequent observation of excimer emission. The bulky pivacac (2,2',6,6'-tetramethylheptane-3,5-dionate) ligand was chosen as the $\mathrm{O}^{\wedge} \mathrm{O}$ ligand in the present study to magnify the steric interactions between the two ligands, to enhance the congestion around the metal centre and to direct the assembly towards an anti-type orientation. Chart 1 summarises the complexes under investigation in this study.

\section{Results and discussion}

\section{Synthesis}

Complex 1 contains an undecorated ppy ligand, L1, and serves as a reference complex (ppy $=2$-phenylpyridinato). The cyclometalating pentafluorosulfanyl $\mathrm{C}^{\wedge} \mathrm{N}$ ligands $\mathbf{L} 2$ and $\mathbf{L} 3$ were synthesized following our previous report. ${ }^{23}$ The synthesis of $\left[\mathrm{Pt}\left(\mathrm{C}^{\wedge} \mathrm{N}\right)\left(\mathrm{O}^{\wedge} \mathrm{O}\right)\right]$ complexes typically proceeds via the formation of mixtures of cis and trans chloro-bridged platinum complexes, in addition to the monomeric complex where one $\mathrm{C}^{\wedge} \mathrm{N}$ ligand is fully cyclometalated and the remainder of the coordination sphere is occupied by a chloride and a second $\mathrm{C}^{\wedge} \mathrm{N}$ ligand that coordinates in a monodentate fashion through the pyridyl nitrogen. ${ }^{26}$ This mixture of intermediates makes isolation of the platinum intermediate difficult. Thus, we modified the synthetic procedure to employ a two-step-one-pot protocol where $\mathrm{K}_{2} \mathrm{PtCl}_{4}$ in the presence of excess $\mathrm{C}^{\wedge} \mathrm{N}$ ligand is refluxed in 2-methoxyethanol to give a mixture of the dimeric and monomeric intermediates. Without isolation of these intermediate platinum complexes, the solvent was removed before excess $\mathrm{K}_{2} \mathrm{CO}_{3}$ and 2,2,6,6-tetramethyl-3,5-heptanedione were added and the mixture stirred at room temperature in a solvent mixture of DCM/MeOH. The complexes were then purified by first filtering through a silica plug to remove platinum impurities and then stirring in hexanes to remove excess 2,2,6,6tetramethyl-3,5-heptanedione. A final filtration resulted in the 
isolation of the pure complexes (yield $=43 \%$ for $1,35 \%$ for 2 and $40 \%$ for 3 ).

\section{Characterisation}

Complexes 1-3 were characterised by NMR spectroscopy $\left({ }^{1} \mathrm{H}\right.$, ${ }^{13} \mathrm{C},{ }^{19} \mathrm{~F}$ ), melting point analysis, high resolution mass spectrometry and elemental analyses. The X-ray structure of 1 has been reported previously ${ }^{12 b}$ while the structures of 2 and 3 have been determined and are compared here to that of 1 . In the ${ }^{1} \mathrm{H}$ NMR spectra, coupling of the high-field (8.9-9.1 ppm) ${ }^{1} \mathrm{H}$ resonances to the $34 \%$ abundant, spin $1 / 2{ }^{195} \mathrm{Pt}$ isotope was observed for all three complexes, indicative of cycloplatination. For complexes 2 and 3, ${ }^{19} \mathrm{~F}$ NMR showed the diagnostic pentet and doublet in a $1: 4$ integral ratio, corresponding, respectively, to the single fluorine atom in a trans relationship with respect to the phenyl ring, and the four fluorine atoms in a cis relationship with the phenyl ring.

Single crystals of 2 and 3 were grown by slow diffusion of hexanes into concentrated DCM solutions. Both complexes display the expected square planar geometry about the platinum centre, with only minimal distortion out of the plane between the two ligands of each complex. In both cases, the shortest metal-ligand bond distance is the $\mathrm{Pt}-\mathrm{C}$ bond, as is typical of cyclometalated transition metal complexes. ${ }^{12 a}$ Complex 1 shows a Pt-C bond length of $1.961 \AA$, which is longer

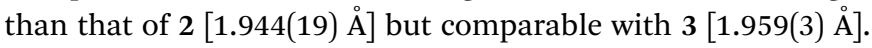
The values obtained through the DFT calculations on the molecules solvated in acetonitrile are $1.962 \AA, 1.955 \AA$ and 1.954 $\AA$ for 1, 2 and 3, respectively. Images of dimers of 1, 2 and 3 are given in Fig. 2.

Complexes 1 and 3 crystallise as dimers, and 2 forms multimeric columns. The pivacac ligands direct all the complexes into anti-configurations. The metal centres adopt a staggered arrangement, leading to long Pt -..Pt distances (5.049 ̊ for 1; $4.686 \AA$ for $2 ; 5.840 \AA$ for 3 ). The longer distances associated with complexes $\mathbf{1}$ and $\mathbf{3}$ are due to metal centres that are offset in two dimensions, while complex 2 is only offset in one dimension so as to minimise steric interactions between adjacent $-\mathrm{SF}_{5}$ units oriented perpendicular to the Pt...Pt axes (Fig. 2).

The presence of the pivacac ligands prohibits the formation of significant Pt-Pt interactions, but encourages $\pi-\pi$ stacking between the $\mathrm{C}^{\wedge} \mathrm{N}$ ligands where the pyridine ring of each dimer forms a close contact with the phenyl ring of the adjacent $\mathrm{C}^{\wedge} \mathrm{N}$ ligand. In contrast to the Pt $\cdots$ Pt distances, the $\mathrm{C}^{\wedge} \mathrm{N}_{\text {pyridine }} \cdots$ $\mathrm{C}^{\wedge} \mathrm{N}_{\text {phenyl }}$ centroid-to-centroid distances of adjacent $\mathrm{C}^{\wedge} \mathrm{N}$ ligands are shorter for $\mathbf{1}(3.932 \AA)$ and 3 (3.916 $\AA$ ) than for 2 (4.036 $\AA$ ); however, these distances are longer than the general range for $\pi-\pi$ stacking, ${ }^{27}$ suggesting any interactions will be weak. The sequential stacking of electron-poor and electronrich aryl rings is a common feature of Pt(II) complexes, ${ }^{\mathbf{1 4 , 2 8}}$ and affects their photophysical properties since the frontier occupied orbitals are mainly localized on the metal and the $\mathrm{C}^{\wedge} \mathrm{N}_{\text {phenyl }}$ orbitals while the LUMO (1) or LUMO+1 (2 and 3) are primarily located on the $\mathrm{C}^{\wedge} \mathrm{N}_{\text {pyridyl }}$ moieties (vide infra). Thus, while the Pt-Pt distance is often invoked to explain the observation of ${ }^{3}$ MMLCT emission, the $\mathrm{C}^{\wedge} \mathrm{N}_{\text {phenyl }}-\mathrm{C}^{\wedge} \mathrm{N}_{\text {pyridine }}$ centroidto-centroid distances are also important parameters that moderate this specific interaction, and provide insight into inter-ligand $\pi-\pi^{*}$ contributions to excimer formation. ${ }^{28}$ The fact that the $\pi-\pi$ distances seen in these complexes are beyond the common range of $\pi$-stacked rings suggests that if this stacking is an influence on the photophysical properties of these complexes, it is likely to be minor.

Finally, examining the extended crystal packing (Fig. 3) of 13 , differences in packing arrangements can be seen in all three complexes. Complex 2 shows columnar structures, as individual complexes interact with those both above and below them to form extended, weakly-interacting chains running along the crystallographic $b$-axis. Complex 3 shows no extended $\pi$-interactions, but adjacent weakly-interacting dimers in the $a c$-plane show the same inclination, forming a sheet arrangement. Adjacent sheets have complexes oriented at approximately $40^{\circ}$ to each other. Complex 1 presents a different behaviour to both 2 and 3. It arises from having two independent molecules of the complex, one of which packs to form dimers, the other of which does not. Dimers in this complex only pack adjacent to each other along the crystallographic $a$-axis; however, non-dimerforming complexes above and below each dimer can also form $\mathrm{C}^{\wedge} \mathrm{N}_{\text {pyridine }}{ }^{\cdots} \mathrm{C}^{\wedge} \mathrm{N}_{\text {phenyl }} \pi$-interactions to the dimer, forming a tetrameric stack. These secondary $\pi$-interactions only involve the pyridine and not the phenyl of the $\mathrm{C}^{\wedge} \mathrm{N}$ ligand of the non-dimer-forming complexes, and exist at a $\mathrm{C}^{\wedge} \mathrm{N}_{\text {pyridine }} \cdots$

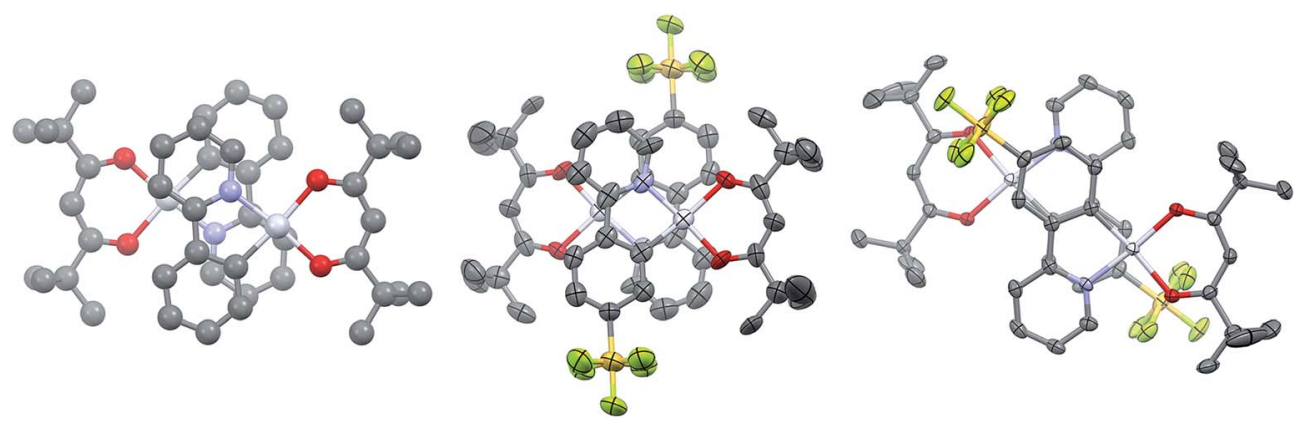

Fig. 2 X-ray crystal structures of dimers of 1, reported by Thompson et al., CCDC 975693 (left); 2 (middle); 3 (right). Thermal ellipsoids of 2 and 3 are drawn at the $50 \%$ probability level. Hydrogen atoms have been removed for clarity. Platinum atoms coloured in silver; nitrogen atoms coloured in blue; oxygen atoms coloured in red; carbon atoms coloured in grey; sulfur atoms coloured in orange; fluorine atoms coloured in yellow. 


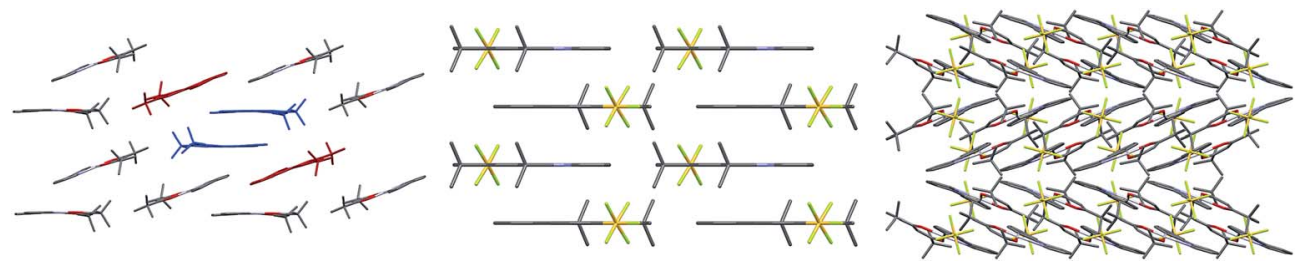

Fig. 3 Packing diagrams of complexes 1-3. Complex 1 (left), viewed down the crystallographic a-axis. One dimer is highlighted in blue, and adjacent non-dimer-forming complexes that give rise to the tetramer are highlighted in red. Complex 2 (middle), viewed down the crystallographic $c$-axis. Polymeric chains run vertically. Complex 3 (right), viewed down the crystallographic $c$-axis, showing the adjacent inclined sheets of dimers.

$\mathrm{C}^{\wedge} \mathrm{N}_{\text {phenyl }}$ centroid-to-centroid distance of $3.927 \AA$, and the nondimer forming complexes are oriented at approximately $20^{\circ}$ to the dimers. As such, all three complexes show independent packing modes.

\section{Electrochemical properties}

Cyclic voltammetry (CV) measurements in MeCN were undertaken to estimate the energy levels of the frontier molecular orbitals of the complexes and to quantify the effects of the $-\mathrm{SF}_{5}$ substituent on their ground state electronics. The CV traces of 1-3 between the first oxidation and first reduction waves are shown in Fig. 4. The full reduction windows of complexes 2 (Fig. S9) and 3 (Fig. S10) are given in the ESI. $\dagger$ The relevant electrochemical data is given in Table 1 . As is characteristic of cyclometalated $\mathrm{Pt}$ (II) complexes, the oxidation waves are poorly resolved and irreversible in nature, pointing towards a principally platinum centred $\mathrm{Pt}^{\mathrm{II}} / \mathrm{Pt}^{\mathrm{III}}$ redox couple. ${ }^{1 a, 12 b}$ The oxidation potential of $1\left(E_{\mathrm{ox}}=1.03 \mathrm{~V}\right)$ is marginally different from the previously reported value $\left(E_{\mathrm{ox}}=1.17 \mathrm{~V}\right)$, which we attribute to the literature value ${ }^{12 b}$ being reported in DMF compared to the current measurement in MeCN.

DFT calculations depict the radical cation spin density of 1-3 as localized on a combination of metal, pivacac and phenyl ring, with the $-\mathrm{SF}_{5}$ mainly playing an inductive role (see Fig. 5). This

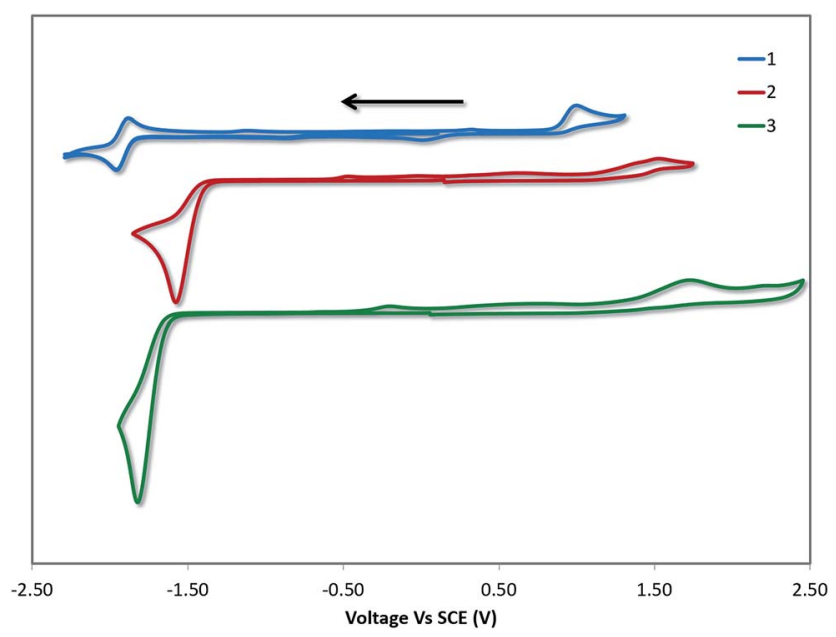

Fig. 4 CV traces of $1-3$ in MeCN solution, reported versus SCE $\left(\mathrm{Fc} / \mathrm{FC}^{+}\right.$ $=0.38 \mathrm{~V}$ in $\mathrm{MeCN}$ ). ${ }^{29}$ Scans are in the negative scan direction at a scan rate of $100 \mathrm{mV} \mathrm{s}^{-1}$. explains the anodic shift of the oxidation potentials of both 2 $\left(E_{\mathrm{Ox}}=1.55 \mathrm{~V}\right)$ and $3\left(E_{\mathrm{ox}}=1.76 \mathrm{~V}\right)$ compared to reference complex 1. The $-\mathrm{SF}_{5}$ group exerts a stronger effect in 3 where it is para to the $\mathrm{Pt}-\mathrm{C}_{\mathrm{C}^{\wedge} \mathrm{N}}$ bond than in $\mathbf{2}$ where it is located meta to this bond. Indeed, the difference in oxidation potential correlates with the Hammett values of the $-\mathrm{SF}_{5}$ group $\left(\sigma_{\mathrm{m}}=0.61, \sigma_{\mathrm{p}}\right.$ $=0.68)$, where the $-\mathrm{SF}_{5}$ acts as an inductively electronwithdrawing group, regardless of its regiochemistry.

There is a less straightforward structure-property trend when considering the reduction potentials of the three complexes. For $\mathbf{1}$, the reduction is reversible in nature $\left(E_{\mathrm{red}}=\right.$ $-1.90 \mathrm{~V}$ ) and is attributed by DFT to the reduction of the pyridine ring of the $\mathrm{C}^{\wedge} \mathrm{N}$ ligand (Fig. 5). By contrast, the first reduction potentials of both $2\left(E_{\text {red }}=-1.57 \mathrm{~V}\right)$ and $3\left(E_{\text {red }}=\right.$ $-1.82 \mathrm{~V})$ are irreversible and multi-electron in nature, which is a behaviour consistent with reduction of the $-\mathrm{SF}_{5} \cdot{ }^{23}$ Indeed, the DFT calculations of the radical anion of 2 and 3 depict a spin density located almost exclusively on this group. This is also in

Table 1 Relevant electrochemical data for complexes $1-3^{a}$

\begin{tabular}{lllll}
\hline Complex & $E_{1 / 2}^{\mathrm{ox}}(\mathrm{V})$ & $E_{1 / 2}^{\mathrm{red}}(\mathrm{V})$ & $E_{1 / 2}^{\mathrm{red} 2}(\mathrm{~V})$ & $\Delta E(\mathrm{~V})$ \\
\hline 1 & 1.03 & -1.90 & - & \\
2 & 1.55 & -1.57 & -2.28 & 3.93 \\
3 & 1.76 & -1.82 & -2.20 & 3.58
\end{tabular}

${ }^{a}$ Measurements were carried out in MeCN at a scan rate of $100 \mathrm{mV} \mathrm{s}^{-1}$ with $\mathrm{Fc} / \mathrm{Fc}^{+}$employed as an internal standard, and reported $v s$. SCE $(\mathrm{Fc} /$ $\mathrm{Fc}^{+}=0.38 \mathrm{~V}$ in $\left.\mathrm{MeCN}\right) .^{29}$

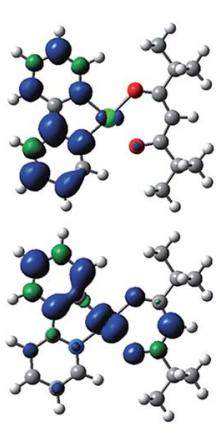

1
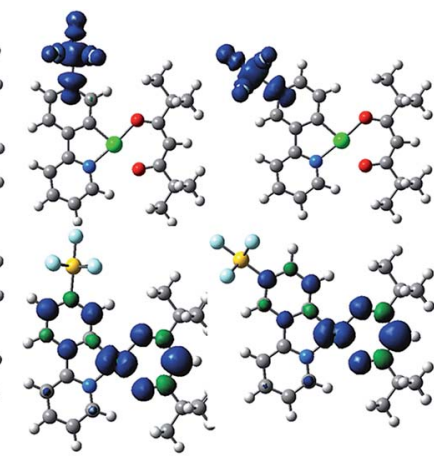

2

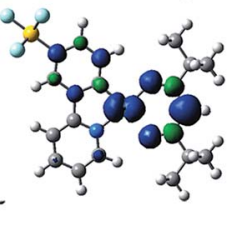

3
Fig. 5 DFT-computed spin density difference plots of the radical anion (top) and radical cation (bottom) of complexes 1-3. 
line with what we had previously observed ${ }^{23}$ with cationic iridium complexes bearing $-\mathrm{SF}_{5}$ substituted $\mathrm{C}^{\wedge} \mathrm{N}$ ligands where their reduction onsets occurred in similar regimes $\left(E_{\text {red }}=\right.$ $-1.60--1.80 \mathrm{~V})$. A second set of reversible reduction waves was observed for 2 and 3 (Fig. S9 and S10 $\dagger$ and Table 1) that we attributed to the analogous reduction of the pyridine ring of the $\mathrm{C}^{\wedge} \mathrm{N}$ ligand that was observed for $\mathbf{1}$. These reduction potentials are significantly more cathodically shifted than the reduction observed in 1, with the value for $2\left(E_{\mathrm{red} 2}=-2.28 \mathrm{~V}\right)$ marginally more negative than $3\left(E_{\mathrm{red} 2}=-2.20 \mathrm{~V}\right)$. Although not a true description of the diradical anion, DFT calculations of the LUMO +1 of 2 and 3 depict orbital plots that are primarily $\mathrm{C}^{\wedge} \mathrm{N}_{\text {pyridyl }}$ in nature (vide infra), which is in line with our assignments.

\section{UV-vis absorption}

UV-vis absorption spectra for 1-3 are shown in Fig. 6 with the data summarised in Table 2. The TD-DFT simulated spectra (Fig. S14†) show that theory reproduces the main experimental trends. At high energy $(250-300 \mathrm{~nm}), \pi-\pi^{*}$ transitions with large extinction coefficients $\left(\varepsilon=2.0-3.1 \times 10^{4} \mathrm{M}^{-1} \mathrm{~cm}^{-1}\right)$, mainly involving the $\mathrm{C}^{\wedge} \mathrm{N}$ ligands, dominate for all three of these complexes. The highest energy transitions for 1 (Expt: $275 \mathrm{~nm}$, Theor: $262 \mathrm{~nm}$ ) and 2 (Expt: $274 \mathrm{~nm}$, Theor: $263 \mathrm{~nm}$ ) are red-shifted compared to that of 3 (Expt: $262 \mathrm{~nm}$, Theor: 255 $\mathrm{nm})$. At longer wavelengths (350-450 nm), broad unstructured absorption bands with smaller extinction coefficients dominate $\left(\varepsilon<1.0 \times 10^{4} \mathrm{M}^{-1} \mathrm{~cm}^{-1}\right)$. For complex 1 , one distinct band can be identified at $362 \mathrm{~nm}$ as well as a less resolved shoulder at $398 \mathrm{~nm}$. TD-DFT predicts the three lowest dipole-allowed transitions at $372 \mathrm{~nm}(f=0.05), 356 \mathrm{~nm}(f=0.01)$ and $355 \mathrm{~nm}(f=$ 0.11). They are principally ascribed to HOMO $\rightarrow$ LUMO, HOMO-2 $\rightarrow$ LUMO and HOMO-1 $\rightarrow$ LUMO transitions, respectively. The MO diagram is given in Fig. 7. It shows that these transitions are predominantly metal-to-ligand charge transfer $\left({ }^{1} \mathrm{MLCT}\right)$ character, as expected, along with some ligandto-ligand charge transfer (LLCT from pivacac to $\mathrm{C}^{\wedge} \mathrm{N}_{\text {pyridyl) }}$ and some intra-ligand charge transfer (ILCT from $\mathrm{C}^{\wedge} \mathrm{N}_{\text {phenyl }}$ to

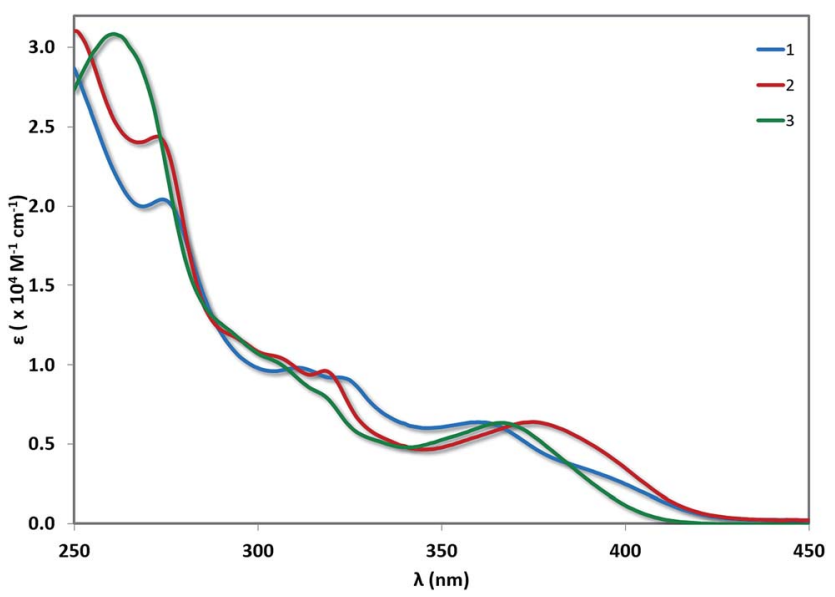

Fig. 6 UV-vis absorption spectra of $1-3$ in aerated MeCN solution at room temperature.
Table 2 Absorption maxima molar absorptivities for complexes $1-3^{a}$

\begin{tabular}{ll}
\hline Complex & $\lambda_{\text {abs }}(\mathrm{nm})\left[\varepsilon\left(\times 10^{4} \mathrm{M}^{-1} \mathrm{~cm}^{-1}\right)\right]$ \\
\hline 1 & $275[2.04], 312[0.98], 325[0.90]$, \\
& $362[0.64], 398(\mathrm{sh})[0.28]$ \\
2 & $274[2.42], 297(\mathrm{sh})[1.13], 307(\mathrm{sh})[1.04]$, \\
3 & $319[0.96], 376[0.64]$ \\
& $262[3.08], 294(\mathrm{sh})[1.18], 307(\mathrm{sh})[0.99]$, \\
& $319(\mathrm{sh})[0.79], 369[0.63]$
\end{tabular}

${ }^{a}$ Measurements were carried out in aerated $\mathrm{MeCN}$ at room temperature.

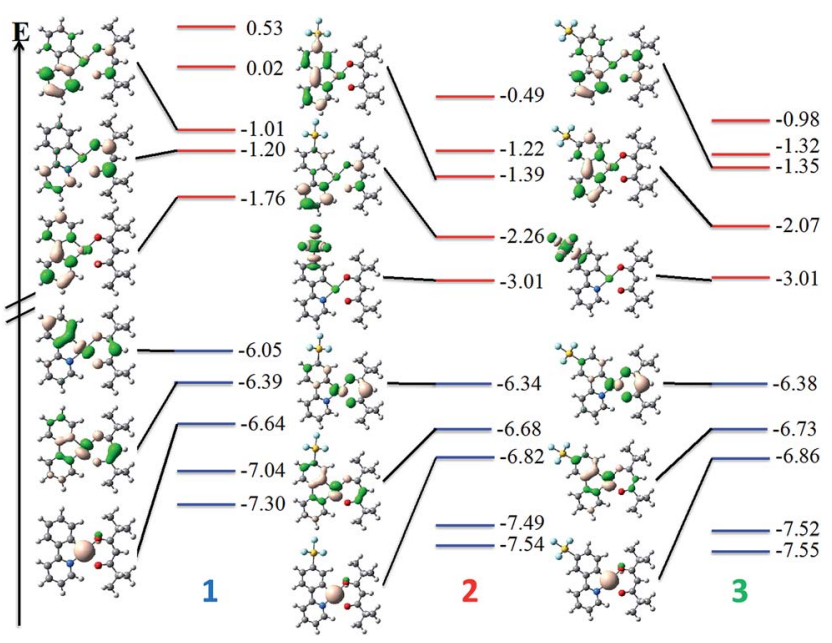

Fig. 7 Representation of the obtained energy levels (in eV) for complexes 1-3 with DFT. The blue and red levels correspond to occupied and unoccupied MOs, respectively. The representation of the six frontier MOs around the gap are given as well.

$\left.\mathrm{C}^{\wedge} \mathrm{N}_{\text {pyridyl }}\right)$. By contrast, only one $\mathrm{CT}$ band is distinguishable for both 2 and 3, with the CT band of 2 (Expt: $376 \mathrm{~nm}$, Theor: 372 $\mathrm{nm}$ ) being modestly red-shifted compared to 3 (Expt: $369 \mathrm{~nm}$, Theor: $350 \mathrm{~nm}$ ). In 2, this band is mainly due to two closely lying excited states according to TD-DFT, the first at $379 \mathrm{~nm}(f=0.09)$ the second at $362 \mathrm{~nm}(f=0.07)$, that both imply transitions from both HOMO and HOMO-1 to LUMO+1, which can be ascribed to CT from the Pt, pivacac and phenyl ring towards the pyridyl moiety. In 3 , the situation is very similar with two states at $357 \mathrm{~nm}(f=0.07)$ the second at $346 \mathrm{~nm}(f=0.09)$ involving the same MOs as in 2. As can be seen in Fig. 7 the LUMO of both 2 and 3 present almost the same energy, and the blue-shift of the CT band in 3 compared to 2 , is related to the slight stabilization of the HOMO orbital in the former complex.

\section{Emission spectroscopy}

The photoluminescence properties of 1-3 were studied in MeCN solution at $298 \mathrm{~K}$ and in the solid state. Their emission profiles in MeCN are shown in Fig. 8, and the relevant photophysical data are given in Table 3. In MeCN solution, the complexes exhibit blue-green to green luminescence. Their emission profiles are highly structured, pointing towards an 


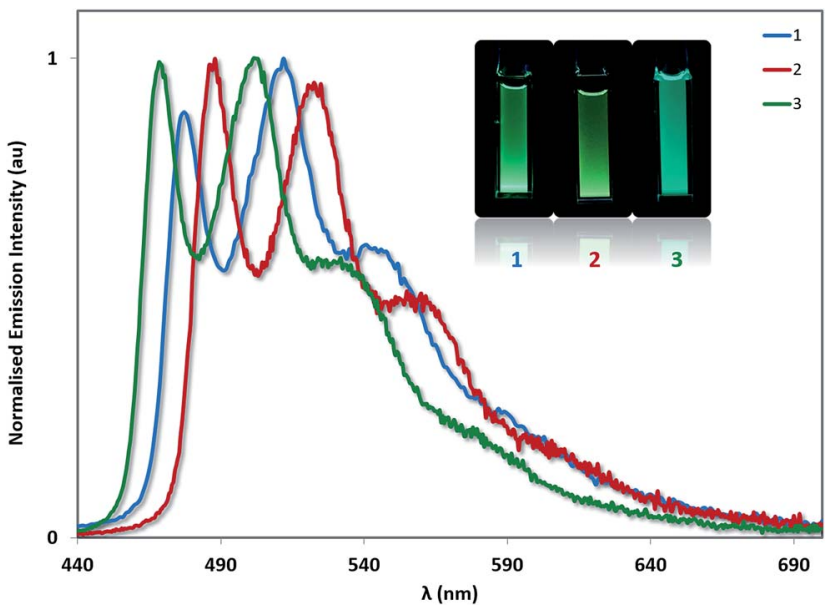

Fig. 8 Solution-state emission spectra of 1-3 in MeCN solution. Inset: photographs of complexes 1-3 in MeCN solution under UV irradiation.

Table 3 Solution-state photophysical data for $1-3^{a}$

\begin{tabular}{llrlll}
\hline Complex & $\begin{array}{l}\lambda_{\mathrm{em}}{ }^{b} \\
(\mathrm{~nm})\end{array}$ & $\begin{array}{c}\Phi_{\mathrm{PL}}{ }^{c} \\
(\%)\end{array}$ & $\begin{array}{l}\tau_{\mathrm{e}}{ }^{d} \\
(\mu \mathrm{s})\end{array}$ & $k_{\mathrm{r}} \times 10^{4} \mathrm{~s}^{-1}$ & $k_{\mathrm{nr}} \times 10^{5} \mathrm{~s}^{-1}$ \\
\hline $\mathbf{1}$ & $477,512,541$ & 22.6 & 2.54 & 8.90 & 3.05 \\
2 & $488,523,561$ & 7.5 & 0.89 & 8.43 & 10.4 \\
3 & $468,502,533$ & 8.4 & 0.88 & 9.55 & 10.4
\end{tabular}

${ }^{a}$ Measurements at $298 \mathrm{~K}$ in deaerated MeCN. ${ }^{b} \lambda_{\text {exc }}: 360 \mathrm{~nm} .{ }^{c}$ Quinine sulfate used as the reference $\left(\Phi_{\mathrm{PL}}=54.6 \%\right.$ in $0.5 \mathrm{M} \mathrm{H}_{2} \mathrm{SO}_{4}$ at $\left.298 \mathrm{~K}\right) .^{33}$ ${ }^{d} \lambda_{\text {exc }}: 375 \mathrm{~nm}$.

excited state that possesses a significant triplet ligand centred $\left({ }^{3} \mathrm{LC}\right)$ character. ${ }^{3} \mathrm{LC}$ emission is common for heteroleptic platinum complexes bearing $\mathrm{O}^{\wedge} \mathrm{O}$-type ligands, as the triplet energies of $\mathrm{O}^{\wedge} \mathrm{O}$ ligands are normally too high for them to participate in the transitions associated with the $T_{1}$ excited state. The photoluminescence quantum yields, $\Phi_{\mathrm{PL}}$, of 2 and 3 in MeCN are significantly lower than of $\mathbf{1}$ despite their somewhat similar emission energies, suggesting that not only does the increased steric bulk of the $-\mathrm{SF}_{5}$ not suppress non-radiative decay channels, this substituent in fact promotes larger non- radiative decay kinetics as evidence by the threefold increase in $k_{\mathrm{nr}}$.

The photophysics for $\mathbf{1}$ have been reported multiple times. In the original report of this complex, the emission maximum in 2MeTHF at $77 \mathrm{~K}$ was found to be $477 \mathrm{~nm} .{ }^{12 a}$ At room temperature, the photophysical properties of $\mathbf{1}$ have been reported in $n$ hexane $\left(\lambda_{\mathrm{em}}=488,524 \mathrm{~nm}, \Phi_{\mathrm{PL}}=15 \%\right),{ }^{30}$ cyclohexane $\left(\lambda_{\mathrm{em}}=\right.$ $\left.485 \mathrm{~nm}, \Phi_{\mathrm{PL}}=33 \%\right),{ }^{12 b} \mathrm{DCM}\left(\lambda_{\mathrm{em}}=485 \mathrm{~nm}, \Phi_{\mathrm{PL}}=35 \%\right),{ }^{30}$ chloroform $\left(\lambda_{\mathrm{em}}=486,518 \mathrm{~nm}, \Phi_{\mathrm{PL}}=19 \%\right)^{31}$ and $\operatorname{THF}\left(\lambda_{\mathrm{em}}=\right.$ $\left.485,519 \mathrm{~nm}, \Phi_{\mathrm{PL}}=16 \%\right)^{32}$ These solvents are less polar than MeCN, which perhaps accounts for the moderate blue-shift we have measured here $\left(\lambda_{\mathrm{em}}=477,512 \mathrm{~nm}\right)$. Our quantum yield $\left(\Phi_{\mathrm{PL}}=22.6 \%\right)$ falls within the range of values previously reported $\left(\Phi_{\mathrm{PL}}=16-35 \%\right)$.

Complex 3 emits the bluest of the three complexes $\left(\lambda_{\mathrm{PL}}=\right.$ $468 \mathrm{~nm}$ for the $E_{0,0}$ band). The higher energy emission also matches with the more stabilised oxidation potential and the more blue-shifted absorption onset for 3 compared to 1 or 2 . Unexpectedly, the emission of $2\left(\lambda_{\mathrm{PL}}=488 \mathrm{~nm}\right.$ for the $E_{0,0}$ band $)$ is red-shifted compared to that of $1\left(\lambda_{\mathrm{PL}}=477 \mathrm{~nm}\right.$ for the $E_{0,0}$ band), despite a moderately more stabilised oxidation potential and essentially identical absorption onset compared to $\mathbf{1}$. Thus, there is no direct connection between the trends observed for ground- and excited-state optoelectronic properties for 2 . Both complexes $\mathbf{2}$ and 3 are less emissive than $\mathbf{1}\left(\Phi_{\mathrm{PL}}=7.5 \%\right.$ for 2 and $8.4 \%$ for 3 ).

DFT computed spin density plots of the $T_{1}$ states (see Fig. S15†) help to explain the divergent ground and excited states behaviour observed in 2. In all cases, these plots show spin density that is delocalised throughout the $\mathrm{C}^{\wedge} \mathrm{N}$ ligand corroborating the assignment of the dominant ${ }^{3} \mathrm{LC}$ character of the emission. In addition, the spin density plots reveal some metal character in the $T_{1}$ state, especially in 2 and 3 . Indeed, we note that the Mulliken $\beta$ charge of the Pt centre is only 0.26 in $\mathbf{1}$ but increases to 0.85 and 0.86 in 2 and 3, respectively. This clearly suggests that there is also a ${ }^{3} \mathrm{MLCT}$ contribution in the emission. In the case of 2 the $-\mathrm{SF}_{5}$ substituent is attached to a carbon atom displaying a strong spin density, and this group therefore directly contributes to stabilizing $T_{1}$. By contrast, in $\mathbf{3}$, the same substituent is attached to a carbon atom acting as a node in the triplet spin density, so that it is not involved

Table 4 Solid-state photophysical data for complexes 1-3

\begin{tabular}{|c|c|c|c|c|}
\hline Complex & $\lambda_{\mathrm{em}}{ }^{a}(\mathrm{~nm})$ & $\Phi_{\mathrm{PL}}^{b}(\%)$ & $\tau_{\mathrm{e}}^{c}(\mathrm{~ns})$ & $\tau_{\mathrm{e}}^{d}(\mathrm{~ns})$ \\
\hline $\mathbf{1}^{e}$ & $488,523,629$ & 6.8 & 73.42 (33\%); 256.8 (42\%); 2316 (25\%) & 801.5 \\
\hline $\mathbf{1}^{f}$ & 520,555 & - & $2118(21 \%), 5653(79 \%)$ & - \\
\hline $2^{e}$ & $494,530,569$ & 7.9 & $13.71(3 \%) ; 393.8(13 \%) ; 2072(85 \%)$ & - \\
\hline $2^{f}$ & $492,528,565$ & - & $1712(18 \%), 6339(89 \%)$ & - \\
\hline $2^{g}$ & $492,528,566$ & - & $448.4(6 \%), 2002(44 \%), 4801(50 \%)$ & $1544(28 \%), 5477$ (72\%) \\
\hline $3^{g}$ & $476,512,555,639$ & - & $153.8(9 \%), 1823(48 \%), 2435(44 \%)$ & 1347 (73\%), $2942(27 \%)$ \\
\hline
\end{tabular}

${ }^{a} \lambda_{\text {exc }}: 360 \mathrm{~nm} .{ }^{b}$ Measured using an integrating sphere. ${ }^{c} \lambda_{\text {exc }}: 375 \mathrm{~nm}$; collected at the principal ${ }^{3}$ LC band. ${ }^{d} \lambda_{\text {exc }}: 375 \mathrm{~nm}$; collected at the principal ${ }^{3} \mathrm{CT}$ band. ${ }^{e}$ Neat film. ${ }^{f}$ Powder emission before grinding. ${ }^{g}$ Powder emission after grinding. 
directly in the $T_{1}$ state, explaining why the emission of 2 is significantly red-shifted compared to both 1 and 3 .

It is difficult to find a family of comparable examples with which to cross compare the optoelectronic properties of complexes 1-3. However, the photophysics of [Pt(ppy)(acac)] (where acac is pentane-3,5-dionate) has been reported in DCM $\left(\lambda_{\mathrm{PL}}=485 \mathrm{~nm}\right) .^{30}$ This value falls between those reported ${ }^{34}$ for two complexes bearing electron-withdrawing - $\mathrm{BMes}_{2}$ substituents in a meta $\left(\lambda_{\mathrm{PL}}=538 \mathrm{~nm}\right)$ and para $\left(\lambda_{\mathrm{PL}}=481 \mathrm{~nm}\right)$ relationship with respect to the $\mathrm{Pt}-\mathrm{C}_{\mathrm{C}^{\wedge} \mathrm{N}}$, analogous to the trend we observe for 1-3.

Aside from its stronger electron-withdrawing nature, the $-\mathrm{SF}_{5}$ moiety is also a large and sterically bulky substituent that can also impact the solid-state packing of these complexes and as a consequence their photophysical properties. To investigate the impact of the $-\mathrm{SF}_{5}$ group on the degree of excimer emission, we recorded the emission spectra of 1-3 as neat thin films by spin-coating concentrated toluene solutions of each complex onto quartz substrates (Fig. 9). It should be noted that in doped films (up to $37 \mathrm{wt} \%$ in a PVK/OXD-7 host), 1 has been shown previously to display ${ }^{3} \mathrm{LC}$ emission almost exclusively from its monomeric state, with minimal red-shifted excimer emission arising from Pt-Pt aggregates. ${ }^{31}$ By contrast, in the neat film we observe predominantly excimer emission as well as some monomeric ${ }^{3} \mathrm{LC}$ contributions for 1 (Table 4 ). The excited state lifetime measured for 1 on the principal ${ }^{3} \mathrm{LC}$ band $\left(\lambda_{\mathrm{em}}: 488 \mathrm{~nm}\right)$ is multicomponent in nature, with a significant contribution from a long-lived component $\left(\tau_{\mathrm{e}}=2.32 \mu \mathrm{s}\right)$ (Fig. S11 $\left.\dagger\right)$. The lifetime measured on the excimeric band $\left(\lambda_{\mathrm{em}}: 629 \mathrm{~nm}\right)$ is single component and shorter $\left(\tau_{\mathrm{e}}=0.80 \mu \mathrm{s}\right)$ (Fig. S12 $\dagger$ ).

The neat film photophysics of 2 and 3 reveal contrasting phenomena. Complex 2 emits exclusively from its monomeric state, while $\mathbf{3}$ mirrors that of $\mathbf{1}$, emitting from a combination of ${ }^{3} \mathrm{LC}$ and excimeric states. The relative intensity of the excimer to the ${ }^{3} \mathrm{LC}$ emission in $\mathbf{1}$ is greater than in $\mathbf{3}$, suggesting that excimer formation is more facile in the case of $\mathbf{1}$ due to the increased steric hindrance conferred by the $-\mathrm{SF}_{5}$ group in $\mathbf{3}$. In

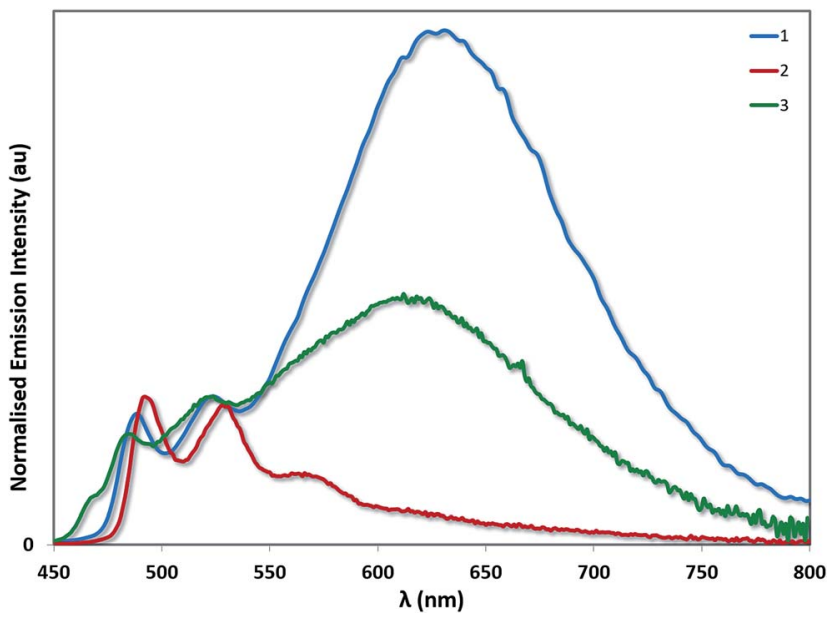

Fig. 9 Solid-state emission spectra of complexes 1-3. The emission profiles have been normalised on the principal ${ }^{3} \mathrm{LC}$ band for each complex. the excited state lifetimes, the ${ }^{3} \mathrm{LC}$ emission of 2 and 3 both have long lived contributions $\left(\tau_{\mathrm{e}}=2.07 \mu\right.$ s for 2 and $1.78 \mu$ s for 3 ). However, only 3 exhibits a single component lifetime base on the excimer band ( $\tau_{\mathrm{e}}=1.35 \mu$ s for 3 ). The quantum yields for 1 $\left(\Phi_{\mathrm{PL}}=6.8 \%\right)$ and $2\left(\Phi_{\mathrm{PL}}=7.9 \%\right)$ are diminished in the solid state, but that of $3\left(\Phi_{\mathrm{PL}}=15.3 \%\right)$ is moderately enhanced.

To determine if the presence of excimeric emission in $\mathbf{3}$ and its absence in $\mathbf{2}$ is directly related to difference between meta and para substitutions, we performed DFT calculations on dimers of these two compounds, considering one of the complex in its $\mathrm{S}_{0}$ geometry and the other in its $T_{1}$ structure. The optimization of these structures led to excimeric dimers presenting very similar interaction energies (see the ESI $\dagger$ ), with distances between the two complexes closer than in the XRD structures, as expected. The TD-DFT calculations performed on the dimer of 2 revealed additional red-shifted transitions compared to the monomer, and the same holds for 3 . This clearly hints that the experimentally observed differences of emission in the solid-state (Fig. 9) are related to the packing of the compounds rather than to their intrinsic electronic structures.

Thus, we can tentatively draw parallels between the solid-state structures and the photophysical properties in the neat film. All three complexes show long Pt-Pt distances in their crystal structures, which precludes ${ }^{3}$ MMLCT states from making a significant contribution to the excimeric state. Indeed, the shortest Pt-Pt distance is observed for complex 2, while this complex displays essentially no excimer emission in the film. Thus the dominant excimer interaction in these complexes is likely to be controlled by inter-ligand $\pi-\pi$ interactions, which although less common, has been reported previously. ${ }^{\mathbf{1 6 a , 3 5}}$ In addition, previously reported theoretical studies on significantly less sterically bulky complexes than 1-3 also argue for significant $\pi-\pi^{*}$ contributions to the excimer, making it plausible that this is the dominant interaction in this instance. ${ }^{\mathbf{1 6 b}}$ Although all three complexes pack differently in the solid-state, the shorter $\mathrm{C}^{\wedge} \mathrm{N}_{\text {pyridine }}-\mathrm{C}^{\wedge} \mathrm{N}_{\text {phenyl }}$ centroid-to-centroid distances of opposing $\mathrm{C}^{\wedge} \mathrm{N}$ ligands measured for $\mathbf{1}(3.932 \AA)$ and 3 (3.916 $\left.\mathrm{A}\right)$ than for complex 2 (4.036 $\AA$ ) might explain our observations of interligand $\pi-\pi^{*}$ emission only from 1 and 3 . Furthermore, the solid-state packing of $\mathbf{1}$ and $\mathbf{3}$ are related by their formation of dimeric structures (with additional secondary interactions in 1 giving rise to tetrameric structures), while by contrast, 2 forms multimeric columnar structures throughout the crystal.

A related trend is observed in the powder photophysics. All the powder samples show green/blue-green luminescence under UV light. However, upon grinding the powders, redshifted excimer emission was observed, demonstrating the mechanochromic properties of 1-3 (see Fig. 10 and S13†). ${ }^{22}$ However, these effects were significantly more pronounced in the case of $\mathbf{1}$ and $\mathbf{3}$, than for $\mathbf{2}$ thereby demonstrating that excimer formation is much more facile in the cases of $\mathbf{1}$ and $\mathbf{3}$. Monomer emission for all three complexes could be restored by redissolving the ground powder in a volatile solvent such as DCM. 


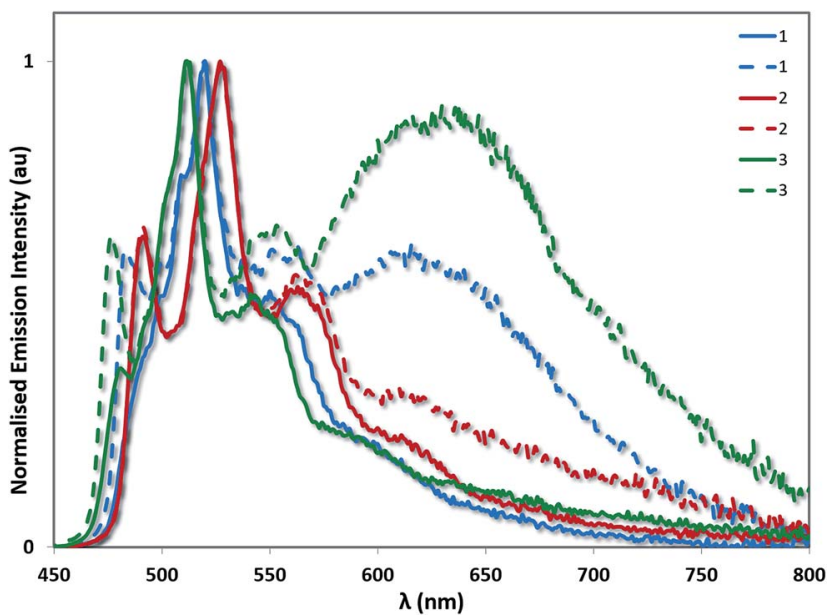

Fig. 10 Powder emission spectra of complexes $1-3$ before (solid lines) and after grinding (dashed lines). The emission profiles have been normalised on the principal ${ }^{3} \mathrm{LC}$ band for each complex.

\section{Conclusions}

Two isomeric $\left[\mathrm{Pt}\left(\mathrm{C}^{\wedge} \mathrm{N}\right)(\right.$ pivacac $\left.)\right]$ complexes 2 and $\mathbf{3}$ bearing strongly electron-withdrawing $-\mathrm{SF}_{5}$ substituents on the phenyl ring of the $\mathrm{C}^{\wedge} \mathrm{N}$ ligand have been synthesised and their optoelectronic properties have been compared to the reference complex $[\mathrm{Pt}(\mathrm{ppy})($ pivacac)], $\mathbf{1}$, where there is no substituent on the phenyl ring. The regiochemistry of the $-\mathrm{SF}_{5}$ exerts a strong effect on the photophysical properties of the complex. In 2, where the $-\mathrm{SF}_{5}$ is in a meta-relationship with respect to the $\mathrm{Pt}-\mathrm{C}$ bond, the emission profile of the complex is red-shifted compared to when there is no $-\mathrm{SF}_{5}$ (1) while in $\mathbf{3}$, the emission is blue-shifted compared to $\mathbf{1}$. This is rationalised on the basis of DFT calculations: in the case of 2, spin-density contributions coming from the $-\mathrm{SF}_{5}$ group lead to a stabilisation of the $T_{1}$ state of 2 relative to 1 and 3 ; in the case of 3 , the $-\mathrm{SF}_{5}$ is situated at a nodal position on the $\mathrm{C}^{\wedge} \mathrm{N}$ phenyl ring, and thus acts only to stabilise the metal-orbitals and thus blue-shift the emission. In the solid-state, the steric bulk (and regiochemistry of this steric bulk) of the $-\mathrm{SF}_{5}$ dictates the capacity of these complexes to display excimeric emission. Complex 1, which has no functionality on the $\mathrm{C}^{\wedge} \mathrm{N}$ ligand, emits from an overwhelmingly $\pi-\pi^{*}$ dominated excimeric state (with only minimal monomeric ${ }^{3} \mathrm{LC}$ contributions). Complex 2 is sensitive to the meta relationship of the $-\mathrm{SF}_{5}$ with respect to the metal centre, showing emission only from the monomeric ${ }^{3} \mathrm{LC}$ state in neat film. The para relationship of the $-\mathrm{SF}_{5}$ with respect to the metal is not enough to dissuade the formation of excimers for this complex, although the intensity of emission relative to monomeric ${ }^{3} \mathrm{LC}$ emission is less pronounced than for $\mathbf{1}$.

\section{Acknowledgements}

EZ-C acknowledges the University of St Andrews for financial support. We thank Johnson Matthey and Umicore AG for the gift of materials. We would like to thank the Engineering and
Physical Sciences Research Council for financial support for Adam Henwood: EPSRC DTG Grants: EP/J500549/1; EP/ K503162/1; EP/L505097/1. We thank the EPSRC UK National Mass Spectrometry Facility at Swansea University for analytical services. DJ thanks the LumoMat RFI project for support. This research used computational resources of (i) the GENCI-CINES/ IDRIS; (ii) CCIPL (Centre de Calcul Intensif des Pays de Loire); (iii) a local Troy cluster.

\section{References}

1 (a) W. J. Choi, S. Choi, K. Ohkubo, S. Fukuzumi, E. J. Cho and Y. You, Chem. Sci., 2015, 6, 1454-1464; (b) C. K. Prier, D. A. Rankic and D. W. C. MacMillan, Chem. Rev., 2013, 113, 5322-5363.

2 (a) Z. Han and R. Eisenberg, Acc. Chem. Res., 2014, 47, 25372544; (b) L. L. Tinker, N. D. McDaniel and S. Bernhard, J. Mater. Chem., 2009, 19, 3328; (c) E. S. Andreiadis, M. Chavarot-Kerlidou, M. Fontecave and V. Artero, Photochem. Photobiol., 2011, 87, 946-964.

3 (a) For recent reviews see: K. K.-W. Lo, M.-W. Louie and K. Y. Zhang, Coord. Chem. Rev., 2010, 254, 2603-2622; (b) K. K.-W. Lo and K. K.-S. Tso, Inorg. Chem. Front., 2015, 2, 510-524; (c) S. W. Botchway, M. Charnley, J. W. Haycock, A. W. Parker, D. L. Rochester, J. A. Weinstein and J. A. G. Williams, Proc. Natl. Acad. Sci. U. S. A., 2008, 105, 16071-16076.

4 (a) D. Ma, T. Tsuboi, Y. Qiu and L. Duan, Adv. Mater., 2017, 29, 1603253; (b) X. Wang, T. Peng, C. Nguyen, Z.-H. Lu, N. Wang, W. Wu, Q. Li and S. Wang, Adv. Funct. Mater., 2017, 27, 1604318; (c) X. C. Hang, T. Fleetham, E. Turner, J. Brooks and J. Li, Angew. Chem., Int. Ed., 2013, 52, 67536756; (d) X. Yang, G. Zhou and W.-Y. Wong, Chem. Soc. Rev., 2015, 44, 8484-8575.

5 V. W. Yam, V. K. Au and S. Y. Leung, Chem. Rev., 2015, 115, 7589-7728.

6 (a) K. J. Lotito and J. C. Peters, Chem. Commun., 2010, 46, 3690-3692; (b) V. A. Krylova, P. I. Djurovich, J. W. Aronson, R. Haiges, M. T. Whited and M. E. Thompson, Organometallics, 2012, 31, 7983-7993; (c) M. Elie, F. Sguerra, F. Di Meo, M. D. Weber, R. Marion, A. Grimault, J. F. Lohier, A. Stallivieri, A. Brosseau, R. B. Pansu, J. L. Renaud, M. Linares, M. Hamel, R. D. Costa and S. Gaillard, ACS Appl. Mater. Interfaces, 2016, 8, 14678-14691.

7 A. F. Henwood, M. Lesieur, A. K. Bansal, V. Lemaur, D. Beljonne, D. G. Thompson, D. Graham, A. M. Z. Slawin, I. D. W. Samuel, C. S. J. Cazin and E. Zysman-Colman, Chem. Sci., 2015, 6, 3248-3261.

8 X. He and V. W.-W. Yam, Coord. Chem. Rev., 2011, 255, 21112123.

9 (a) J. Kalinowski, V. Fattori, M. Cocchi and J. A. G. Williams, Coord. Chem. Rev., 2011, 255, 2401-2425; (b) B. X. Yang, C. Yao and G. Zhou, Platinum Met. Rev., 2013, 57, 2-16; (c) K. Li, G. S. Ming Tong, Q. Wan, G. Cheng, W.-Y. Tong, W.-H. Ang, W.-L. Kwong and C.-M. Che, Chem. Sci., 2016, 7, 1653-1673. 
10 (a) P. K. Chow, C. Ma, W.-P. To, G. S. M. Tong, S.-L. Lai, S. C. F. Kui, W.-M. Kwok and C.-M. Che, Angew. Chem., Int. Ed., 2013, 52, 11775-11779; (b) P.-K. Chow, G. Cheng, G. S. M. Tong, C. Ma, W.-M. Kwok, W.-H. Ang, C. Y.-S. Chung, C. Yang, F. Wang and C.-M. Che, Chem. Sci., 2016, 7, 6083-6098; (c) Z.-Q. Zhu, T. Fleetham, E. Turner and J. Li, Adv. Mater., 2015, 27, 2533-2537.

11 (a) C. Bronner and O. S. Wenger, Dalton Trans., 2011, 40, 12409-12420; (b) M. Zhang, C. Zhu and L.-W. Ye, Synthesis, 2017, 49(6), 1150-1157.

12 (a) J. Brooks, Y. Babayan, S. Lamansky, P. I. Djurovich, I. Tsyba, R. Bau and M. E. Thompson, Inorg. Chem., 2002, 41, 3055-3066; (b) A. Bossi, A. F. Rausch, M. J. Leitl, R. Czerwieniec, M. T. Whited, P. I. Djurovich, H. Yersin and M. E. Thompson, Inorg. Chem., 2013, 52, 12403-12415.

13 (a) A. F. Rausch, L. Murphy, J. A. G. Williams and H. Yersin, Inorg. Chem., 2011, 51, 312-319; (b) A. Rausch, H. Homeier and H. Yersin, ed. A. J. Lees, Organometallic Pt(II) and Ir(III) Triplet Emitters for OLED Applications and the Role of SpinOrbit Coupling: A Study Based on High-Resolution Optical Spectroscopy, Photophysics of Organometallics, Springer, Berlin/ Heidelberg, 2010, pp. 193-235.

14 W. B. Connick, R. E. Marsh, W. P. Schaefer and H. B. Gray, Inorg. Chem., 1997, 36, 913-922.

15 A. Aliprandi, D. Genovese, M. Mauro and L. De Cola, Chem. Lett., 2015, 44, 1152-1169.

16 (a) J. A. Bailey, M. G. Hill, R. E. Marsh, V. M. Miskowski, W. P. Schaefer and H. B. Gray, Inorg. Chem., 1995, 34, 4591-4599; (b) D. Kim and J.-L. Brédas, J. Am. Chem. Soc., 2009, 131, 11371-11380.

17 (a) C. Zhou, L. Yuan, Z. Yuan, N. K. Doyle, T. Dilbeck, D. Bahadur, S. Ramakrishnan, A. Dearden, C. Huang and B. Ma, Inorg. Chem., 2016, 55, 8564-8569; (b) M. Han, Y. Tian, Z. Yuan, L. Zhu and B. Ma, Angew. Chem., Int. Ed., 2014, 53, 10908-10912.

18 T. Fleetham, L. Huang and J. Li, Adv. Funct. Mater., 2014, 24, 6066-6073.

19 M. Atoji, J. W. Richardson and R. E. Rundle, J. Am. Chem. Soc., 1957, 79, 3017-3020.

20 (a) S. B. Ko, H. J. Park, S. Gong, X. Wang, Z. H. Lu and S. Wang, Dalton Trans., 2015, 44, 8433-8443; (b) C.-H. Chen, F.-I. Wu, Y.-Y. Tsai and C.-H. Cheng, Adv. Funct. Mater., 2011, 21, 3150-3158.
21 V. W.-W. Yam, K. M.-C. Wong and N. Zhu, J. Am. Chem. Soc., 2002, 124, 6506-6507.

22 (a) M. Krikorian, S. Liu and T. M. Swager, J. Am. Chem. Soc., 2014, 136, 2952-2955; (b) A. Han, P. Du, Z. Sun, H. Wu, H. Jia, R. Zhang, Z. Liang, R. Cao and R. Eisenberg, Inorg. Chem., 2014, 53, 3338-3344; (c) Y. Sagara, S. Yamane, M. Mitani, C. Weder and T. Kato, Adv. Mater., 2016, 28, 1073-1095.

23 N. M. Shavaleev, G. Xie, S. Varghese, D. B. Cordes, A. M. Z. Slawin, C. Momblona, E. Ortí, H. J. Bolink, I. D. W. Samuel and E. Zysman-Colman, Inorg. Chem., 2015, 54, 5907-5914.

24 P. R. Savoie and J. T. Welch, Chem. Rev., 2014, 115, 11301190.

25 (a) V. N. Kozhevnikov, Y. Zheng, M. Clough, H. A. Al-Attar, G. C. Griffiths, K. Abdullah, S. Raisys, V. Jankus, M. R. Bryce and A. P. Monkman, Chem. Mater., 2013, 25, 2352-2358; (b) A. F. Henwood, A. K. Bansal, D. B. Cordes, A. M. Z. Slawin, I. D. W. Samuel and E. Zysman-Colman, J. Mater. Chem. C, 2016, 4, 3726-3737; (c) G. G. Shan, H. B. Li, H. Z. Sun, H. T. Cao, D. X. Zhu and Z. M. Su, Dalton Trans., 2013, 42, 11056-11065.

26 J.-Y. Cho, K. Y. Suponitsky, J. Li, T. V. Timofeeva, S. Barlow and S. R. Marder, J. Organomet. Chem., 2005, 690, 4090-4093.

27 C. Janiak, J. Chem. Soc., Dalton Trans., 2000, 3885-3896.

28 Y.-J. Cho, S.-Y. Kim, H.-J. Son, D. W. Cho and S. O. Kang, Phys. Chem. Chem. Phys., 2017, DOI: 10.1039/ C1036CP08651A.

29 V. V. Pavlishchuk and A. W. Addison, Inorg. Chim. Acta, 2000, 298, 97-102.

30 C. Karakus, L. H. Fischer, S. Schmeding, J. Hummel, N. Risch, M. Schaferling and E. Holder, Dalton Trans., 2012, 41, 9623-9632.

31 D. Kourkoulos, C. Karakus, D. Hertel, R. Alle, S. Schmeding, J. Hummel, N. Risch, E. Holder and K. Meerholz, Dalton Trans., 2013, 42, 13612-13621.

32 (a) Z. M. Hudson, B. A. Blight and S. Wang, Org. Lett., 2012, 14, 1700-1703; (b) S. W. Thomas Iii, S. Yagi and T. M. Swager, J. Mater. Chem., 2005, 15, 2829.

33 W. H. Melhuish, J. Phys. Chem., 1961, 65, 229-235.

34 Y.-L. Rao, D. Schoenmakers, Y.-L. Chang, J.-S. Lu, Z.-H. Lu, Y. Kang and S. Wang, Chem. - Eur. J., 2012, 18, 11306-11316. 35 V. M. Miskowski and V. H. Houlding, Inorg. Chem., 1989, 28, 1529-1533. 